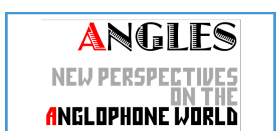

ANELOPHONE WORLD

\section{Angles}

New Perspectives on the Anglophone World

1 | 2015

Brevity is the soul of wit

\title{
One-liners and Linguistics: (Re)Interpretation, Context and Meaning
}

\section{Catherine Chauvin}

\section{(2) OpenEdition}

1 Journals

\section{Electronic version}

URL: https://journals.openedition.org/angles/2138

DOI: 10.4000/angles.2138

ISSN: 2274-2042

\section{Publisher}

Société des Anglicistes de l'Enseignement Supérieur

\section{Electronic reference}

Catherine Chauvin, "One-liners and Linguistics: (Re)Interpretation, Context and Meaning", Angles [Online], 1 | 2015, Online since 01 November 2015, connection on 08 June 2022. URL: http:// journals.openedition.org/angles/2138 ; DOI: https://doi.org/10.4000/angles.2138

This text was automatically generated on 8 June 2022.

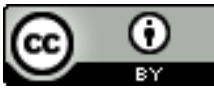

Angles est mise à disposition selon les termes de la Licence Creative Commons Attribution 4.0 International. 


\title{
One-liners and Linguistics: (Re)Interpretation, Context and Meaning
}

\author{
Catherine Chauvin
}

1 Whether they stand on their own, or are part of a longer routine ${ }^{1}$, one-liners, or "short jokes", have a self-contained quality: they can be considered as a unit, and they are supposed to produce an immediate comic effect. They could be considered to be the condensed version of a joke, but a difference can be made between one-liners and (longer) jokes: because of their very brevity, there is little or no room for elaboration in one-liners, whereas jokes could be thought to constitute short comic narratives. In this paper, we would like to discuss one-liners from the perspective of linguistics, focusing on one approach in particular: we would like to examine the kind of insight one-liners can provide on how meaning emerges contextually. If an interpretation, arguably the same for every listener, is thought to have to be computed very quickly and then perhaps changed, they may allow one to discuss the reality and nature of potential "default" interpretations. As one-liners are short and (apparently) self-contained, the input of the context may also seem to be limited, so that the way in which a given interpretation is supposed to emerge has to be clarified. Their comedic value should not entirely be ignored either, since, as we will see, the connection between interpretative problems and comedic value may not be entirely straightforward.

2 In order to discuss these questions, we will first propose a typology of one-liners in which we will describe some of the recurrent devices used in this comic form, and discuss some aspects of their classification; then we will come back synthetically on what the examples can reveal about "interpretation" processes. Finally, we will briefly discuss the question of one-liners as a comedic genre, and initiate a discussion of how form and function interact. 


\section{A typology of one-liners}

Attempts at compiling lists of logical mechanisms or devices underpinning jokes (e.g. Hetzron 1991, Attardo 2001, Attardo et al. 2002) may be correct but cannot be said to be exhaustive beyond a shadow of a doubt, given language users' creativity in constructing jokes. (Dynel 2009: 10)

We will first try to write a commented typology of one-liners, which, although it will be several pages long, attempts to be short and synthetic. We will, for the time being, make few references to pre-existing typologies, which do exist ${ }^{2}$, but tend to concern jokes rather than one-liners as such-Dynel (2012) being an exception, since she started with one-liners and later extended her approach to jokes. In other terms, we will also try to keep in mind what makes one-liners specific. ${ }^{3}$

4 One-liners are of varied nature and the only common points they seem to have is that they are short and are supposed to be funny. They can be found in a series of possible forms and formats, and can be linked to different comedic traditions. Even though oneliners (particularly, perhaps, the pun-based ones) tend to be associated with traditional formats, a number contemporary comedians also make use of one-liners, sometimes specializing in dirty or offensive uses of them (cf. Tim Vine or Jimmy Carr in the U.K.; some of their lines are mentioned in the examples below). While one-liners seem to share one common point, i.e. their length, here too there may be some variation.

In this study, we have compiled approximately 15,000 one-liners taken mostly from two books (Tibball 2012, Tucker 2012), as well as from a few other individual sources (see references below). They can be strictly speaking one-line-long if we take "line" in the typographic sense, but they tend to be at least two lines long, and sometimes slightly longer; in grammatical terms, they may be one sentence, but they can be made of up to four sentences ${ }^{4}$. When they are uttered orally, one could think that the Conversation Analysis unit "turn" could form an interesting describing tool for one-liners-except that a number of one-liners are to be found in monological routines, where there is no, or very little, turn-taking at work. This can, in turn, lead us to take "line" in the theatrical sense of the word, but (as was just said) if one-liners can contitute one short (theatrical) line, they can also be part of a larger monologue. What could make them independent units is their environment: there is little, or no, continuity with what precedes or follows them. But there may be recurrent themes in a show, and further reference can be made to a given one-liner in the course of a routine. This said, the brevity of one-liners does seem to be linked to a form of self-containment, which has to be taken into account, but which we will also try to challenge in this paper.

6 Another problem lies in the fact that other recognized genres or sub-genres can be characterized by their linking of brevity and humour: riddles, pick-up lines and retorts to such lines ("comebacks"); not all of them are funny, but some of them are supposed to be, so that there may be partial overlap between the categories. Puns are frequently found in jokes, but although one-liners are very often based on puns (as we shall see), puns are not used solely in one-liners. Certain codified comedic forms may also be found and some of them may be found in longer form, such as stupid blonde jokes or my wife/ girlfriend... jokes (again, see below for more details). Outside of the Englishspeaking world, the French bon mot, or even the notorious blagues Carambar ${ }^{5}$ could be classified as one-liners too. Finally, one-liners based on observational humour may also, in turn, come to resemble proverbs, or wisdom writings. 
7 A one-liner is, therefore, short and funny. One-liners do seem to have a number of characteristics in common and can (often) be recognized intuitively, but the boundaries of the genre may be hard to establish. Despite the differences, a number of recurring patterns and devices can be found, and a rough classification proposed. There may be a number of borderline or complex cases, but in the vast majority of examples, one-liners can fall under at least one of the following broad categories.

For the purposes of this paper, we will propose a typology that is partly connected with the main linguistic device they are based upon, since one-liners are often-but not always-made possible by some property of language that is played upon/with. But not all one-liners are strictly speaking based on a given device, as we will see; nevertheless, they are always at least partly linguistic inasmuch as they rely on language (they are verbal games). To speak of a main device does not mean, of course, that it is the only device that is to be found in a given one-liner. The classification will provide us with a general backdrop to analyse some examples more specifically as we go beyond this initial typology.

\subsection{Pun-based one-liners}

9 A large number of one-liners rely on puns. ${ }^{6}$ Puns have been extensively discussed in the literature-if one humorous device is discussed, it tends to be puns, which are sometimes treated as the "simplest" cases (Ritchie 2004), which we will argue they are not. They may not be the funniest of one-liners, although this can be cultural thing or a question of taste; Ritchie in fact says that puns can be met with groans, rather than laughter. This partly goes beyond the limits of this paper, although (as was said before) a few elements having to do with the connection between form and comedic value will be examined below in our last section.

Puns may be assumed to function at the lexical level only, i.e. revolve around the interpretation of "one word"; two of the word's meanings, or uses, are activated at the same time, or alternatively. This needs clarification. What the writer and/or the comedian seems to be taking advantage of is polysemy, or, rather, the multiple uses of a word (in bold, below):?

(1)

a. I entered a swimming contest at the weekend. I won the $100 \mathrm{~m}$ butterfly. What am I going to do with an insect that big?

b. The judge has got a stutter, so it doesn't look like I'm getting a sentence.

c. I told a volcano joke down the pub last night. The whole place erupted.

d. My friend is sick to death of people always taking the piss out of him for having brittle bone disease. One day he's going to snap.

e. My doctor told me that I had to give up drinking. It's been three days now and I feel really dehydrated.

f. Windmills: big fan; big, big fan.

g. Every time I hear a joke, I throw up. It must be my gag reflex.

h. I've reached the age where I can't function without glasses. Especially if they're empty.

i. I ordered a whole duck at a Chinese restaurant last night. It was great until I got to the bill.

j. Menstrual jokes are not funny. Period.

k. Two soldiers are in a tank. One looks at the other and goes, 'Blublublub!'

1. There are two fish in a tank. One turns to the other and says, 'Do you know how to drive this thing?' 
m. My girlfriend said she wanted me to tease her, so I said "Alright, fatty." (Jimmy Carr)

$\mathrm{n}$. When you eat a lot of spicy food, you can lose your taste. When I was in India last summer, I was listening to a lot of Michael Bolton. (Jimmy Carr)

Although lexical puns always seem to be involved, all these examples do not function in the same way. The way in which drinking in (1e) is first made to bring to mind the idea that someone is drinking alcohol may not be a specific use but a common pragmatic inference when the verb is used intransitively; the fact that tease can be interpreted in $(1 \mathrm{~m})$ as being "nice" or "rough" teasing (the spectrum of teasing can go from gentle bantering to near-insult) may also have to do with pragmatics, not semantics; the same could perhaps be said to what taste applies to in (1n). Others may just be cases of homophony, with the usual complications encountered when a tight distinction is supposed to be made between homophony and polysemy: bill (beak/cheque) or tank in examples $(1 \mathrm{i}, \mathrm{k}, \mathrm{l})$, could be cases at hand. The tests that can be used to make a distinction between homonymy and polysemy-for instance, Cruse (2004)'s use of anaphora-would suggest that tank has uses that are too different for a simultaneous or very close activation of both senses to be possible; yet, the opposition between the two meanings has been used (more or less) successfully in the preceding examples. The way in which lexical forms are used in such cases could show that the types of differences may not entirely matter, as long as two interpretations can be made to emerge; it might at least be important to note that they may not all be of the same form.

Other types of wordplay are of course possible: two words are just homonymous when they just sound the same, and two words are at least supposed to be distinct when they are spelt differently:

(2)

a. I just saw a beautiful girl with a massive gut. What a waist.

This may not operate at word-level only:

(2)

b. I'm about to have a cup of dangerous coffee. Safe tea first.

c. There's no need for women to behave the way they do on their period. It's an ovary action.

One speaks of paronomasia, or paronymy, when the words do not quite sound the same, but almost do:

(3)

a. Avalanche: what Italians do every day at about half past twelve. (have a lunch) ${ }^{8}$

b. My granddad doesn't like fried chicken, but my Nandos.

c. 11:59:59 a.m. is my favourite time of the day. It's second to noon.

e. So this lorry full of tortoises collided with a van full of terrapins. It was a turtle

disaster. (Tim Vine)

b. Programmers do it beta. ${ }^{9}$

The word game may be based on the form of the word(s) itself, and different types of such formal puns are possible. Visual puns based on spelling could be assumed to have to be used in written form only, but, as is shown by (4), it is not necessarily the case:

(4)

a. Why oh why don't people poof read stuff before they post it?

b. I have a friend who's half Indian. Ian.

c. You can't spell 'prostitution' without 'STI'. 


\section{two meanings to emerge:}

(4)

d. I was in a spelling bee once. But I lost because the other students cheeted.

e. The spell czech on my computer has never failed me yet.

In the case of (4c), the visual pun is also a lexical pun ('STI'). The processes can be used together, which again shows that they should not be thought of as exclusive.

\subsection{Set phrases}

Another large number of one-liners are based on set phrases. This is interesting per se: set phrases have been considered to be non-transparent forms in which the relationship between form and meaning is (somewhat) fixed, but it has also been shown that it is not necessarily the case (Mejri 2005): although they are supposed to be frozen, they, in fact, can often be modified. ${ }^{10}$ Here are a few examples:

(5)

a. The easiest way to add insult to injury is when you're signing somebody's plaster cast.

b. There's a race war going on in my kitchen. It all started when the pot called the kettle black.

c. I've got a friend who has got a butler whose left arm is missing-serves him right! (Tim Vine)

d. Crystal balls: I don't know what people see in them.

e. It pains me to say it, but I have a sore throat.

f. I love my satnav. I don't know where I'd be without it.

g. Some people say it's hard being a hostage. Pfff... I could do it with my hands tied behind my back.

h. I'm so good at sleep, I can do it with my eyes closed.

this case, is also rather strikingly the less salient"11, meaning is (also?) "activated". An opposition could be made with the preceding cases in which simple words seemed to be concerned, but as we will see below, thinking that interpretation only operates at the word-level even for the preceding examples might be a mistake. The structure of the next two examples is complex: the whole one-liner comes to be read as a retake on a proverb that is not stated in full:

(6)

a. I've just finished building Rome with my nephew's Lego. Took me a day.

b. I eat an apple every day. The wife's a doctor.

\subsection{Structural, or syntactic, ambiguity}

Another linguistic phenomenon that can be made use of is ambiguous syntax. It does seem rarer than word- or fixed-expression-based puns-the rarity is also noted in Dynel (2012)-, but examples can be found:

(7)

a. Reincarnation is making a comeback.

b. I'm not worried about the Third World War. That's the Third World's Problem.

(Jimmy Carr)

c. Throwing acid is wrong, in some people's eyes. (Jimmy Carr) 
d. I live near a remedial school. There is a sign that says, slow... children. That can't be good for their self-esteem. (Jimmy Carr)

e. My wife is fed up of my wordplay jokes. I asked, 'What can I do to stop my addiction?' She said, 'Whatever means necessary.' 'No it doesn't,' I said.

f. I saw a sign in a shop: 'Mosquito nets €10.' I didn't even know bugs could play the lottery.

g. I made a chicken salad last night. Apparently they prefer to eat grain.

h. I went to the game and saw a Mexican wave, so I waved back at him. also be taken to be pragmatic in nature; certain examples may be more openly based on problems traditionally ascribed to pragmatics, not semantics. The type of commonness to be found in the next two examples could be linked to the presence of conventional implicatures:

(8)

a. You know that look you get from women when they want you? Nah, me neither.

And the famous Groucho Marx line can also be mentioned here:

b. A child of 5 would know this. Bring me a child of 5 ! (Groucho Marx)

Indirect speech acts may also be made to be interpreted literally, which brings this case close to that of certain set expressions, although the way in which they have come to be fixed may be different. The illocutionary level is ignored:

(9)

a. I saw a sign in a car park saying: "Thieves want your satnav." I thought, "Well, they can get lost!"

b. So I rang up a local building firm, I said "I want a skip outside my house." He said "I'm not stopping you." (Tim Vine)

Certain discursive or conversational clichés (rather than idioms / collocations), may also be used, as in:

(10)

My girlfriend bought a cookbook the other day called "Cheap and easy vegetarian cooking". Which is perfect for her, because not only is she vegetarian... (Jimmy Carr) 
this is the first part of a common discursive phrase, the missing half can probably be expected and reintroduced by the hearer(s). Some interpretations are also based on reference problems, rather than meaning. The following example may seem to be another instance of lexical ambiguity, but in fact, the word is taken to refer to distinct realities. What is at stake is reference rather than meaning, and the possibility of referring to different things in turn creates a form of interpretative ambiguity:

(11)

A Chinese couple are in bed. The husband says "I want a sixty-nine." His wife says,

"You want beef and broccoli now?"

This is also linked to world knowledge or culture, ${ }^{12}$ as one needs to know how meals are referred to in Chinese restaurants in order to understand it.

The following cases could still be linked to a form of reference taken in a broader sense, but they are of a more specific kind: they rely on cultural knowledge, rather than linguistic devices (see discussion below). They include hints, quotations or fragments of quotations (12c), reference to known social practices (12i), to a person's or a brand name (12a), a book, a commercial (12d), etc.

(12)

a. Maybe it's Maybelline... and maybe it's Photoshop.

b. Fox is so twentieth century.

c. My wife has just left me for Arnold Schwarzenegger. She'll be back.

d. African child dies? I watched those, and couldn't help thinking, "Well, stop clicking your fingers!" (Jimmy Carr)

e. I'm officially changing my remote's name to Wally.

f. And that, Romeo, is why we usually try to take a pulse first.

g. Chaos: what erupts when he-who-lives-in-a-glass-house invites he-who-iswithout-a-sin for dinner.

h. So Batman came up to me \& he hit me over the head with a vase \& he went T'PAU! I said "Don't you mean KAPOW??" He said "No, I've got china in my hand." (Tim Vine, referring to an 80s pop song by T'Pau, 'China in Your Hand', 1987) i. Some guy just gave me half of a peace sign.

The fact that these examples suppose cultural knowledge is incidentally revealed by the presence of those in example (12d); its use shows that what is referred to is supposed to belong to the speaker and hearer's shared knowledge. Such one-liners may rely on the pleasure of recognizing a reference (see Section 3); they also make it necessary to 'get' the reference if they are to be understood at all. They may also lead to a reinterpretation of a situation rather than a word or phrase; the link that is made between remote controls and Where's Wally? books in (12e) casts in a new light the fact that people tend to leave their remote controls in hidden places. This makes some of them close(r) to the next types of examples.

\subsection{Logical fallacies, observational and absurdist humour}

The next series of examples are also language-based (they have to be), but no longer use language self-referentially: they involve an analysis, or a striking representation of a situation, a specific take on the world.

One recurrent type is based on logical fallacies: non sequiturs, tautologies, logical reinforcement of a contradiction... Mental diseases seem to form a frequent topic in one-liners based on self-contradiction: a type of behaviour is described, and what is described proves that the fictional speaker and patient has the disease that $s /$ he is 
claiming not to have. This creates a "discrepancy" between what is said and what is implied to be the case.

(13)

a. All we ever do is ask questions: why?

b. I'm a very good ventriloquist, even though I say so myself. (combined to a conversational cliché)

c. There are two types of people: those with Alzheimer's.

d. I was thinking of writing a book, A Guide to Better Shoplifting-but who the hell is going to buy it?

e. If you quit rehab, does that mean it worked?

f. Statistically, three in one people have schizophrenia.

g. My mate told me I just don't understand irony. Which was ironic because we were at the bus stop at the time.

h. My friends say I'll believe anything. Damn, I suppose they're right.

i. People call me Mr Compromise. It wasn't my first choice for a nickname, but I can live with it.

j. My friends say I'm too easy to please. I was delighted when they told me.

k. I'm not paranoid, but I'm sure people think I am.

1. I parked my car sideways over two disabled spaces. "What's wrong? You look in perfect health to me," said the guard. "Schizophrenia," we replied.

$\mathrm{m}$. My girlfriend just left me because I'm so lazy. Insert your own punchline here.

(combined with the "my girlfriend..." pattern, see 1.6. below)

Another way of pointing out the absurdity of something is to propose a matter-of-fact combination of data that reveals an oddity. This form of observational humour is typically found in stand-up comedy routines, although for practical reasons we have also drawn these examples from our book collections:

(14)

a. If you're trying to improve your memory, lend someone money.

b. Breaking news: "Man lucky to be alive after being hit by a train." I think I'm

luckier: I've never been hit by a train.

c. For just $£ 10$ a month you can reduce your annual salary by $£ 120$.

d. I saved loads of cash on the new iPhone yesterday. I didn't buy one.

e. Hey Timex, if I end up $660 \mathrm{ft}$ under water, I'm pretty sure I won't need a watch.

(combined with cultural reference to an advertisement)

f. Regular naps prevent ageing. Especially if you take them while driving.

g. Liven up your local library by hiding all the books on anger management.

In these cases, a whole (often, common) situation is cast in a new light, and the audience / reader is invited to think differently about it. The strangeness of a situation can just be emphasized; some silly one-liners may remain surprising, or absurd:

(15)

a. Snakes: they're like bits of rope, only angrier.

b. Apparently, 1 in 5 people in the world are Chinese. And there are 5 people in my family, so it must be one of them. It's either my mum or my dad. Or my older brother Colin. Or my younger brother Ho-Chan-Chu. But I think it's Colin. (Tim Vine)

\subsection{One-liner versions of joke templates}

Finally (for the purposes of this typology), there are types of one-liners that can be considered to form templates, some of which are common to longer jokes (cf. stupid blonde jokes), others which are perhaps more specifically short because of their very characteristics (yo-mamma jokes). They could be considered to constitute sub-genres 
because of their recurrent characteristics and they form patterns writers have to embrace and play with. Here are a few examples.

- Yo-mamma jokes: generally in the form Your mum is so $X$ that $Y$, they are a form of ritualized insult originally linked to the African-American community in the U.S., but they can now be found elsewhere. The speaker insults someone else's mother and shows their own superiority by coming up with something clever and inventive:

(16)

a. Your mum's so stupid she went to DFS and bought a full-prize sofa.

The pattern can be extended to other types of hyperbolic one-liners of the Your X is so $Y$ that $Z$ types; the speaker is supposed to be clever and inventive in his/her exaggeration again:

(16)

b. Your head is so big that your ears are in different time zones.

- My wife/girlfriend jokes: usually in the first person (and with a supposed male speaker), they describe something that the wife or girlfriend blames a man for. This is followed by a comeback, or by something that, as in the mental disease examples, confirms the presence of what the girlfriend reproached the man with in the first place.

(17)

a. My wife says I'm full of my own importance. Anyway that's enough about her...

b. My wife's leaving me because she's apparently fed up of me "quoting her all the time".

- Definitions. They emulate dictionary definitions but are either silly (cf. observational humour and/or absurdist humour), or may involve a pun; they are a specific pattern, but some of the forms mentioned earlier may be found again - (12g) was already of this type-:

(18)

a. Exaggeration: without it the world would end.

b. Anti-gravity: it never lets you down.

-... walks into a bar jokes. This is a famous template for jokes in the English-speaking world which may sometimes also be used in one-liners:

(19)

Two dragons walk into a bar. One dragon says, "It's warm in here." The other says,

"Shut your mouth."

- Another well-known type of jokes is the stupid blonde joke, which may also be found in oneliners, although they also tend to be longer jokes. Here is just one example amongst many:

(20)

I cheated on my blonde girlfriend and she found out. Which made her unsure if the baby was hers.

Other cases could also be mentioned, such as light bulb jokes (How many $X$ does it take to change a light bulb?), but they tend to be riddles, i.e. a specific kind of form that may or may not (truly) count as a one-liner, and nationality-based jokes (as in: A Frenchman, a Scotsman and an Englishman walk into a bar...), which also tend to be longer jokes because they usually need some minimal space for elaboration. Although examples (16)-(20) form recurrent templates, the characteristics found in these one-liners can still be linked to other cases, as shown earlier, but the fact that they constitute (semi-)fixed forms can be included in the forthcoming discussion (in Section 3, in particular).

The following table summarizes the types of one-liners discussed in this section. The headings provided in the left column are an indication of possible groupings for the devices mentioned in the right column, but it should be noted, again, that they may not constitute entirely separate categories, or tiers. The set forms of jokes are visually 
separated from the others because they can be thought to operate at a different level; this is briefly taken up in the discussion (Section 3).

Table 1. A summary of the types of one-liners presented in section 1 in relation to the main devices used

\begin{tabular}{|c|c|}
\hline Pun-based (words) & $\begin{array}{l}\text { (1) puns, polysemy } \\
\text { (2) puns, homonymy } \\
\text { (3) puns, paronymy } \\
\text { (4) puns, visual and formal }\end{array}$ \\
\hline Set phrases & $\begin{array}{l}\text { (5) set phrases: meaning of set phrases } \\
\text { (6) indirect allusions to phrases / incomplete phrases }\end{array}$ \\
\hline Ambiguous syntax & (7) ambiguous syntax \\
\hline Pragmatics / discourse-based & $\begin{array}{l}\text { (8) implicatures, diverse cases } \\
\text { (9) implicatures, indirect speech acts } \\
\text { (10) discursive / conversational clichés } \\
\text { (11) lexical, but reference } \\
\text { (12) cultural references }\end{array}$ \\
\hline Logical fallacies; observational humour & $\begin{array}{l}\text { (13) internal contradictions (with example of diseases) } \\
\text { (14) observational humour: gnomic statements } \\
\text { (15) absurdist humour: absurd, silly... statements }\end{array}$ \\
\hline $\begin{array}{l}\text { + Set-types of jokes: (16) Yo mamma } \\
\text { Walks into a bar jokes; (20) Stupid b }\end{array}$ & $\begin{array}{l}\text { (17) My wife/ girlfriend jokes; (18) Definitions; (19) } \\
\text { jokes... }\end{array}$ \\
\hline
\end{tabular}

As was announced earlier, we will now discuss what the abovementioned examples can say about the emergence of meaning in context. What we will try to show is what oneliners can bring to the discussion; the combination of some of the factors we are about to examine is, in particular, part of the problem. Let us therefore try and see what oneliners have to say about (re)interpretation processes, and contextual meaning.

\section{One liners, (re)interpretation, and contextual meaning}

In a number of examples, one interpretation could be supposed to be formed by the reader / audience, a second interpretation is also formed, and it could seem that the discrepancy between both interpretations might be a/the source of humour. This could perhaps for instance be said of examples (1)-(4), (5)-(6), (7), (8)-(11), and perhaps (12). The case of examples (13)-(15) can be brought into question, although they, in fact, might not be the best counter-examples, as we shall see below. Is this analysis correct? If there is such a double interpretation, how can its emergence be accounted for; what is an "interpretation"? It seems necessary to go into some detail and name some of the parameters at stake. 


\subsection{Interpretation/reinterpretation and merged interpretation}

general:

One of the first conceptualisations of jokes' structuring is credited to Hockett (1972/1977), according to whom, a joke comprises a build-up and a punch. (Dynel 2012: 7)

It might even be truer of one-liners which, as said earlier, do not allow for an elaboration phase because of their brevity. It could be supposed, then, that the following pattern is the norm and constitutes the basic form for one-liners:

build-up: interpretation 1 ,

followed by punch: reveal, interpretation 1 is wrong $\rightarrow$ interpretation 2

A number of one-liners could be described in this way, such as in examples (1a) and $(1 \mathrm{e}):^{13}$

(1)

a. I entered a swimming contest at the weekend. I won the $100 \mathrm{~m}$ butterfly.

What am I going to do with an insect that big?

e. My doctor told me that I had to give up drinking. It's been three days now and

I feel really dehydrated.

In these examples, the second part of the joke reveals an interpretation that was not available in the first part. This model quickly reaches its limits, however, something which Dynel (2012) has brought into focus, showing that one-liners are not all based on the "garden path" mechanism, i.e. following a pattern in which a first part leads the listener astray, before a second part reintroduces a new, "correct", meaning. "Garden path" is not a term that Dynel invented for the analysis of jokes: the term refers to sentences in which a first meaning is supposed to be computed and then rejected, because something makes it impossible to keep the first interpretation. A well-known example of such sentences is The horse raced past the barn fell, which is not humorous. ${ }^{14}$

We would like to agree with Dynel, but we can perhaps go one step further: does the comparison with garden path sentences truly apply even for some jokes that seem to fall under this category? In The horse raced..., no first, "full", meaning is ever achieved, or, at any rate, the "first" meaning has to be abandoned-some examples of garden path sentences discussed in Bever (1970) are in fact difficult to interpret, and the paper is a reflection on what makes something interpretable. Dynel (2012) often uses the term "cancel" to refer to what happens to the "first" interpretation. In our examples, the "first" meaning may not, in fact, be cancelled, and it often is not. Even in (1a), the insectbutterfly is supposed to have been won at a swimming competition: in other words, the swimming is part of the content of the situation in which butterfly is intended to mean insect; the cancellation, if it exists, is incomplete. The two contexts are, in fact, merged, instead of having one interpretation cancelled and another one replacing / erasing it. In many cases, interpretations (i.e., here, the result of the interpretation, so to speak: how they are probably understood) are not cancelled at all: a given form is made to have several meanings at once, or sequentially. This is the case of examples $(1 b, c, d, \ldots)$ :

(1)

b. The judge has got a stutter, so it doesn't look like I'm getting a sentence.

c. I told a volcano joke down the pub last night. The whole place erupted. 
d. My friend is sick to death of people always taking the piss out of him for having brittle bone disease. One day he's going to snap.

g. Every time I hear a joke, I throw up. It must be my gag reflex.

h. I've reached the age where I can't function without glasses. Especially if they're

empty. reinterpretation, but multiple interpretation, successive or simultaneous, and, even, merged. In other words, part of the pleasure might come from the fact that the meaning is enriched and unstable and multiple, and not, or not necessarily, that there is one, and then another way of understanding it. Even though some interpretations might be made to become salient later in the relatively short process of "getting" a oneliner, in the end interpretations can be, or tend to be merged, i.e. they are not kept separate. of, what has just been said. Dynel (2012) has rightly pointed out that one given mechanism has been thought to be more systematically present than is really the case. But although we agree that the typology of jokes must be enriched and complexified, perhaps focusing on where and/or how the "reveal" takes place ${ }^{17}$ might not be of the essence if one is supposed to be dealing with multiple interpretations. Maybe this also focuses too much on interpretation as the selection of one clear, pre-defined option (as is sometimes the case in analyses that are based on "multiple"-i.e. discrete-meanings, or tiers).$^{18}$ The crossroads mechanism is called this way because the hearer is supposed to be metaphorically at a crossroads, i.e. he/she is possibly hesitating between two discrete, separate options. But are they discrete and separate? Where it happens might not necessarily prove central to distinguish whether the mechanism itself is (perhaps partly) the same. Focusing too much on discrete, separate, internally logical worlds may also be something that the "incongruity approach" to humour (used, among others, by Dynel) could be criticized for. ${ }^{19}$ The fact that something is deemed incongruous is 
sometimes linked to the idea that it conflicts with "the standards of the real world," or "conflicting with one's knowledge of the world" (Dynel 2012). But do we actually have (logically) organized, self-contained areas which we refuse to combine? We may sometimes seek representations of this kind when constructing theoretical models, but doubt whether these models truly correspond to natural representations of the world. All in all, all of this supposes that meanings are discrete, (automatically?) processed, and that the interpretation of a one-liner can be delineated in terms of what it is, ie. it could be "spelt out" entirely. Because worlds may vary from one individual to another, perhaps another question could be be: spelt out for, or by, whom? And yet, one-liners often do seem to be based on interpretations supposedly commonly accessed by several independent speakers. In the next sub-section, we will discuss this possible paradox.

\subsection{Default/preferred readings}

52 Can interpretations be expected to be the same for all hearers, or, for that matter, for the deviser and the hearer? A number of one-liners seem to rely on the hope, on the deviser's part, that the same (mis-)assumptions will be made, and then that reinterpretations will work in a common way-hopefully, the same for all members of the audience, and, hopefully, the same as the one expected by the deviser. This could suggest that there is a preferred collective interpretation, one sometimes taken for granted as the default, or preferred, reading-a notion which is not necessarily challenged. ${ }^{20}$ But this is, in fact, an interesting, but complex, problem in itself, and we will try to see how a (fixed, set, predetermined) default reading may not necessarily need to be posited, although we do believe that there are several sides to this problem. The issue is (partly) related to that of whether interpretations are discrete, since a common interpretation would probably have to be discrete for it to be truly "common", although that might not be entirely necessary. At this point, we could distinguish between default meaning and default interpretation: one is ascribed rigidly and acontextually to a given entity, the other one is computed and constructed contextually.

The fact that a number of set phrases, clichés (linguistic or cultural), and references are used probably ensures that certain assumptions are made, but it does not follow that it is an automatic, rather than a dynamic, process. A number of one-liners use forms that are relatively set, making one particular interpretation more plausible; although there may not be direct form-to-meaning equivalence, a certain interpretation may be entrenched enough for it to come to mind quickly. ${ }^{21}$ There might be some sort of priming (i.e., something comes to mind first) at work.

Lexical ambiguity does not necessarily allow for such immediate priming, except if one use is much more common than others, and therefore "salient"-but the question is known to be a thorny one: prototypes may play a role here, or frequency, or both. Now it is doubtful whether there is an a-contextual preferred interpretation for glass or tank; there probably is not. The cases that are based on puns may be the most old-fashioned types, but they are not the simplest cases to explain-quite the contrary. In such cases, (relatively) discrete interpretations seem to come to mind (in other words, it is possible, and often easy, to paraphrase the "meaning" of the word), but this interpretation is not a default meaning at the level of langage. It could nevertheless be assumed that a use is made salient at the level of langue. 

forms: they are self-contained because they need not be, and often are not, enclosed in a coherent narrative (with something coming before it and something coming after it), but they are also linked to a cultural context which means that not everything has to be computed from the one-liner itself. In fact, a small proportion of what is understood may be. Besides, even if one-liners are short, they also provide contextual, i.e. cotextual, clues, in particular for cases of linguistic ambiguity, which could be analysed in terms of frayage ("path-opening", Culioli), even though we might be using this notion in a larger sense that just the presence of one given utterance that paves the way for interpretation ("énoncé précurseur", Culioli 1990: 124). We agree here with the suggestion made in Jaszczolt (2010) when she proposes that interpretation is not a question of semantics first, or semantics only, and then pragmatics, but that interpretation may be constructed with the interaction of both levels. Given the abovementioned examples, the contextual clues that can be found in them despite their brevity provide sufficient background for one possible interpretation to be made prominent, although not exclusive:

(1)

a. I entered a swimming contest at the weekend. I won the $100 \mathrm{~m}$ butterfly.

e. My doctor told me that I had to give up drinking.

h. I've reached the age where I can't function without glasses.

k. Two soldiers are in a tank.

1. There are two fish in a tank.

n. When you eat a lot of spicy food, you can lose your taste.

Both interpretations may be opened at the same time, or successively, and some of the hints may even have to be understand retrospectively (but probably remain in the listener's mind when s/he hears the rest of the line, without necessarily requiring any effort, particularly if the one-liner is used orally):

(1)

b. The judge has got a stutter, so it doesn't look like I'm getting a sentence.

c. I told a volcano joke down the pub last night. The whole place erupted.

d. My friend is sick to death of people always taking the piss out of him for having brittle

bone disease. One day he's going to snap.

g. Every time I hear a joke, I throw up. It must be my gag reflex.

i. I ordered a whole duck at a Chinese restaurant last night. It was great until I got to the bill.

Interpretation is a combination of co-textual and cultural clues, which will probably lead members of the audience that belong to the same, or partly similar, cultural and linguistic background to reach the same conclusion. For one-liners, which can work as self-contained units, an interpretation may need to be at least minimally opened to occur, but the self-contained co-text of the one-liner is not the only clue that comes into play. So several interpretations may be permitted successively or conjointly by the lexical and cultural knowledge of the hearer; they are contextually constructed and, therefore, primed (priming being an active process in this case). As said earlier, contextual opening need not just be lexical: the position in a sentence, for instance, may also constitute such an interpretation-building hint:

(1j). Menstrual jokes are not funny. Period.

The use of period in a final, isolated position brings "full stop"' to mind. The opening is not lexical, but constructional, so to speak. Other contextual elements may play a role, such as intonation (which will not be discussed here); but they may all contribute to 
bring to the fore one interpretation that will probably be of the same kind for a given group of people who share a certain cultural and linguistic background.

A set phrase might constitute its own opening, as frequency and (semi-)fixedness can allow for conventional, salient interpretations; co-textual information may become less necessary because there is one "default" reading for set phrases, or, rather, a commonplace, frequent reading-conventional is not the same as default. The less common interpretation is probably going to be the one that needs more overt opening as it is less immediately available. This can account for their strong presence in oneliners, since they vastly facilitate the deviser's (and the hearer's) work. But fixedness and set default meanings do not necessarily need to be posited to explain how a given interpretation is constructed in certain one-liners.

In cases of structural ambiguity, interpretation can also go both ways. But, again, cotextual elements are still present, and, again, context is also cultural, as can be illustrated by I made chicken salad (7g), in which one of the situations is evidently more probable than the other; the same can be said for Third World War (7b), or for slow... children (7d), in which the second meaning is made more apparent when that can't be good for their self-esteem is added. But this is something that is only likely to be present in a given hearer, because of what they know, culturally, linguistically-all of this is a matter of probability and of comparative saliency, and a sort of (safer, or less safe) bet on the part of the deviser, which also means that the deviser can fail. This also suggests that culture and co-text function together to create such saliency (although not necessarily entirely in the same way). Pragmatics and semantics both play a role, as is mentioned in Jaszczolt $(2005,2010)$, but this might not call for "default" (pre-counted, discrete) interpretations. And it does not mean that all hearers will hear it in the same way, or that it will be understood by an "ideal" hearer in the fixed, discrete form that the deviser had in mind. ${ }^{22}$

\subsection{To what extent are language-based one-liners specific?}

We have just mentioned language and culture, showing that one-liners can be both opposed, with the use of different devices, all the while being connected, given that language and cultural references need not be opposed at a more general level. One question that can finally be discussed is whether previous remarks on interpretation apply only, or mostly, to language-based one-liners (puns, etc.), or whether they can be extended to cultural cases, too. The process of creation of multiple interpretations is perhaps generally present in all examples, and could be extended to cases that do not openly rely on linguistic material, such as examples (12), which reinforces the idea that one-liners are not always based on linguistic ambiguity:

(12)

a. Maybe it's Maybelline... and maybe it's Photoshop.

b. Fox is so twentieth century.

c. My wife has just left me for Arnold Schwarzenegger. She'll be back.

d. African child dies? I watched those, and couldn't help thinking, "Well, stop

clicking your fingers!" (J. Carr)

e. I'm officially changing my remote's name to Wally.

f. And that, Romeo, is why we usually try to take a pulse first.

g. Chaos: what erupts when he-who-lives-in-a-glass-house invites he-who-iswithout-a-sin for dinner. 
h. So Batman came up to me \& he hit me over the head with a vase and he went “T'PAU!" I said "Don't you mean KAPOW??" He said "No, I've got china in my hand." (Tim Vine)

i. Some guy just gave me half of a peace sign.

In these examples, some light (not necessarily "new", as old clichés may also be confirmed) is shed on a given situation, by drawing together contexts that may not usually function together, such as in the way in which the wife "will be back" in (12c), or the comparison between the impossibility of finding a remote control and finding Wally in (12e). But it is also a form of merger, where knowledge of a given context comes to enrich the knowledge of a first context, without there being any (total?) cancellation, and without there being any need to posit two opposed, separate contexts. ${ }^{23}$ In cases linked to observational humour, the previous way of seeing something has been enriched, but nothing has necessarily been cancelled and replaced with a new belief. So in the end, the opposition between what is based on language and what is based on culture may not be entirely relevant at this level of the analysis. Merged interpretations could be sought in a number of cases regardless of the (main) device upon which they are based. The device provides the tool that is used, and the merged interpretation is (one of) the result(s) ${ }^{24}$ that is sought by someone using a one-liner. Reanalysis may be present in the logical fallacy examples as well, but here too, the second part does not cancel the first; the effect comes from the connection of both parts, not from the fact that the first part is cancelled because the second part contradicts it; this would in fact make the whole line pointless:

(13)

a. All we ever do is ask questions: why?

b. I'm a very good ventriloquist, even though I say so myself.

c. There are two types of people: those with Alzheimer's.

d. I was thinking of writing a book, A Guide to Better Shoplifting-but who the hell is going to buy it?

e. If you quit rehab, does that mean it worked?

f. Statistically, three in one people have schizophrenia.

g. My mate told me I just don't understand irony. Which was ironic because we were at the bus stop at the time.

h. My friends say I'll believe anything. Damn, I suppose they're right., etc.

This said, understanding a one-liner does not necessarily make it funny, which leads us to the last part of this paper, in which we will make brief remarks on the comic value of one-liners and its links with the question of interpretation.

\section{Now, is this funny? Felicitousness and infelicitousness, or: one-liners, genre and creativity}

The preceding remarks have sometimes led us to leave aside an important aspect of one-liners: they are supposed to be funny. Certain studies sometimes seem to equate the question of understanding a one-liner with the fact of finding it funny, thinking that explaining how they can be understood explains away what they are, and is sufficient to account for their humorous value. This, however, is not the case. If we use one of Austin's terms which pragmatics literature often resorts to, one could say that oneliners may be more or less felicitous. Two conditions may be required for them to be felicitous: a) they should be understood; b) they should be thought funny. But even though it might perhaps be better if they are conjoined, these conditions can be 
independently met. Understanding a joke may not mean that the joke is considered funny, and a joke might be considered funny even if it is not understood-as when only parts of the joke are understood, or when the joke is misunderstood (a case we do not have space to discuss here), or when the delivery itself causes laughter. Incidentally, this again shows that incongruity does not necessarily account for the presence of humour, since a joke that is already known may still be considered funny-or not-if told with brio, used in the right context, etc.

The funniness of a one-liner is of course hard to define, and is probably contextdependent, (sub-)genre dependent, and even, sometimes, simply idiosyncratic. The pleasure of recognizing a good pun, of seeing several meanings at once, may already constitute a form of felicity, without necessarily creating an uproar-some people may have a taste for puns, others find them stale and 'easy'. Understanding a merged representation of something such as (13e) can lead to laughter, a smile, or perhaps, occasionally, just interrogation ("finally, does it?"). The sub-genres mentioned earlier may also come into play now, as they have become templates audiences can be used to: recognition of the type of jokes may cause pleasure (or displeasure), and creativity within a given pattern is what an audience may go for. Cultural recognition of a pattern may help a hearer recognize that the joke is a joke, ${ }^{25}$ and might also constitute a template against which the current joke is assessed. Yo-mamma jokes seem to be based on a sense of creativity: if you find an original connection and outwit your adversary, your line can be deemed good. But this is also (sub-)genre-dependent: paradoxically, paranomasia-based one-liners may be most appreciated when they are "not" good, i.e. when they are almost infelicitous; the more approximate and risky they are, the better they can be thought to be. Different types of horizons of expectations can also be at work in relation to a given comedian, a series of films, a type of show, sometimes in relation to the use of such and such a device, as well. Tim Vine is famous for his collection of pun-based one-liners that come in quick succession. His audience may expect series of complex puns, and the more complex, the better. In Jimmy Carr's case, the audience may be getting ready to see how risqué his one-liners can get: the ruder, the better. Woody Allen's one-liners can be expected to be wry, etc.

What was said before about contextual interpretation is partly independent of this, since we have said that interpretation and humour are not necessarily linked. But there are, in fact, possible connections between the interpretation of one-liners, their comedic value and their forms; the two dimensions (interpretation / comedic value) may work together but may also turn out to be conflictual. Heavy opening, for instance, can make a pun much more understandable, but totally unfunny. The lines also ought to be written in a way that makes it possible to deliver them orally, and this can bring limitations to how syntactic ambiguity can be used, as was pointed out before, since a given parsing may call for specific intonation. Interpretation and comedic value are not one and the same thing, but the humorous dimension of one-liners may in fact have implications on the very shape that interpretation-building devices are allowed to have.

\section{Conclusions}

In this paper, we have looked at one-liners from a linguistic(s) point of view, and in so doing, we have pointed out a number of questions that they seem to illustrate and 
which are often central to linguistic theory: default meaning(s), saliency/priming, the role of context, what an interpretation can be, the respective role of the semantic and pragmatic tiers, for instance.

We have tried to show that the interpretation of one-liners was a dynamic process, and suggested that merged interpretations play a very important role, as opposed to successive discrete interpretations in which one interpretation cancels out the other. Dynel (2012) is correct when she argues that more patterns exist than the one in which there is a late cancellation of a first hypothesis, but the process of cancellation needs further inquiry. Although incongruity may be present in a number of cases, a few arguments stemming from the incongruity theory of humour have also been discussed (i.e. something incongruous is not necessarily funny and something funny is not necessarily incongruous), and we have pointed out some aspects of the interaction between the humorous dimension of one-liners and the fact that they may need to be at least interpretable-more opening may make a line more understandable, for instance, but a heavy opening might ruin the comedic effect, suggesting that conflicting strategies may be at stake.

Lastly, we have suggested that interpretability is not the same thing as comedic value. While some studies suggest that a one-liner is explained when its meaning(s) are made clear(er), understanding something does not make it funny; it could be a prerequisite, but even that point may be challenged. The perception of humour may be highly context-dependent (i.e. dependent on genre, on the hearer's tastes and expectations, on the hearer's perception of the speaker, etc.), which might make a given one-liner felicitous for some in a certain context, but not for others in another. While additional issues would require further study, we hope to have shown that one-liners are, or can be, good revealers of linguistic problems, and perhaps other, broader subjects as well.

\section{BIBLIOGRAPHY}

Attardo, Salvatore. Linguistic Theories of Humour. Berlin: Mouton de Gruyter, 1994.

Aaron, Debra. Jokes and the Linguistic Mind. London: Routledge, 2012.

Carroll, Noel. Humour: A Very Short Introduction. Oxford: Oxford UP, 2014.

Cruse, Alan. Meaning in Language: An Introduction to Semantics and Pragmatics. $3^{\text {rd }}$ edition. Oxford: Oxford UP, 2011.

Clark, H.H. Using Language. Cambridge/New York: Cambridge UP, 1996.

Culioli, Antoine. "Formes schématiques et domaine", Pour une linguistique de l'énonciation, Tome 1, Opérations et représentations. Paris: Ophrys, [1987]1990. 115-126.

Dynel, Marta. Humorous Garden-Paths: A Pragmatic-Cognitive Study. Newcastle: Cambridge Scholars Publishing, 2009.

Dynel, Marta. "Garden Paths, Red Lights and Crossroads: On Finding Our Way to Understanding the Cognitive Mechanisms Underlying Jokes”. Israeli Journal of Humor Research 1.1 (2012). 6-28. 
http://www.israeli-humor-studies.org/media/1-

_garden_paths,_red_lights_and_crossroads,_marta_dynel \%D7\%A1\%D7\%95\%D7\%A4\%D7\%99_19_\%D7\%99\%D7\%95\%D7\%A0\%D7\%99

Fauconnier, Gilles. Espaces mentaux. Paris: Les Editions de Minuit, 1984.

Gréciano, Gertrud. Signification et dénotation en allemand. La sémantique des expressions idiomatiques. Metz: Université de Metz, 1983.

Gross, Gaston. Les expressions figées en français. Paris: Ophrys, 1996.

Jaszczolt, Katarina. Default Semantics: Foundations of a Compositional Theory of Acts of Communication. Oxford: Oxford UP, 2005.

Jaszczolt, Katarina. "Default Semantics". The Oxford Handbook of Linguistic Analysis. Ed. B. Heine \& H. Narrog. Oxford: Oxford UP, 2010. 193-221.

Levinson, Stephen. Pragmatics. Oxford: Oxford UP, 1983.

Mejri, Salah. "Figement absolu ou relatif : la notion de degré de figement". Linx 53 (2005):

183-196. DOI: 10.4000/linx.283

Ritchie, Graeme. The Linguistic Analysis of Jokes. London: Routledge, 2004.

Sanz, Montserrat, Laka, Itziar, and Tanenhaus, Michael K. Language Down the Garden Path: The Cognitive and Biological Basis for Linguistic Structures. Oxford: Oxford UP, 2013.

\section{Corpus/one-liners}

Tibballs, Geoff, ed. The Mammoth Book of One-Liners. London: Robinson, 2012.

Tucker, Grant. 5,000 Great One-Liners. London: Robson P., 2012.

Best, Steve. Comedy Snapshots. London: Articul8 Publishing, 2014.

Vine, Tim. The Biggest Ever Tim Vine Joke Book. London: Century, 2010.

\section{Stand-up comedy shows}

The stand-up comedy shows that were mostly used and cited for this study are Jimmy Carr's and Tim Vine's, and more especially Jimmy Carr, Laughing and Joking, 2013, Channel 4 DVDs. Groucho Marx lines have been compiled from the films themselves, and Duck Soup in particular has been viewed again in relation to this study. Woody Allen quotes had also originally been compiled. Unfortunately, they have not made it into the final version of this paper. This sad fact may recall one of Allen's quips: "The other day I was alone and a man came up to me and kept saying over and over again, 'You're a star, you're a star.' I thought, this year I'm a star, but what will I be next year-a black hole?”

\section{NOTES}

1. It should be noted that, in this paper, "routine" is used as in "stand-up routine", a term used by comedians to refer to their show, and often more specifically, the sequentially ordered content of the show. It is therefore not synonymous with "pattern", or "template", which are also used in the paper to refer to codified forms for one-liners and jokes.

2. We cannot say that "there is no currently no theory of how humour works" (Ritchie 2004, introduction). There is a long tradition of trying to account for humour, linguistically (e.g., 
Attardo 1994) but also more generally: the incongruity theory, the superiority theory, the relief theory; Freudian analyses, Aristotelian analyses, Kantian analyses, Bergsonian analyses, etc. What may be true is that there is no recognized theory of how it works, since how and when humour appeared is still very much a mystery. We will not delve into these debates in this paper; among many other possible sources, see for instance Carroll (2014). A few aspects of the incongruity theory are discussed in the course of the paper, however.

3. Aaron (2012) proposes a general classification of jokes, not one-liners, specifically, assigning them to the syntax, phonetic, semantic... tiers of language. We have not tried to follow this, or one, predefined classification as we tried to focus on what seemed to be relevant to this analysis. A presentation of Dynel (2012)'s typology, which is part and parcel of her approach, will nonetheless be included in Section 2 .

4. This statement supposes that we know what a sentence is, which is not necessarily true.

5. Daft, children-directed short jokes or riddles that are printed on the back of the paper wrappers of Carambar, a caramel sweet.

6. We will not put forward any statistics because they would be entirely irrelevant: despite the large size of the collections (approx. 15,000), they are not taken to be qualitatively representative.

7. Meanings are stable and lexicalized. Uses are values that are associated to certain contexts.

8. This is reminiscent of the Italian-pronunciation-based puns to be found in Chico's dialogues in the Marx Brothers movies. Some of the dialogues in the Marx Brothers films can in fact be considered to be a quick succession of one-liners.

9. This, of course, works better in non-rhotic varieties of English.

10. For the very large literature on the topic, cf. for instance Mejri (2005), Gréciano (1983), Gross (1996).

11. Since "literal" meaning is often (wrongly) assumed to be the easier and more salient meaning.

12. Culture is taken here to mean: what you know because you are part of a community that shares a certain number of assumptions and values.

13. The aforementioned one-liners are reproduced again in this section to facilitate the reading of the analysis; also, we will underline new aspects in bold to draw the reader's attention to what is being discussed in this Section.

14. The example is discussed in Bever (1970) and reprinted in Sanz, Laka \& Tannehaus (2013).

15. Dynel also uses the term salient, but a shift in saliency is not the same thing as a cancelled meaning, and even a shift in saliency might not (always) be what is involved.

16. I wish to thank an anonymous reviewer for suggesting I should draw more attention to this example.

17. Dynel proposes "a tripartite division of jokes in reference to their incremental development" (Dynel 2012: 7; bold added for emphasis): "three major mechanisms of linear joke comprehension can be distinguished, depending on the stages and means of incongruity emergence and incongruity resolution". For the record, as the crossroads mechanism is also mentioned further down in this paragraph, the typology she proposes is the following: a) the "garden path mechanism", where the hearer is led to have one interpretation and then to change it; b) the "red-lights mechanism", where new, incongruous material is added and has to be integrated into what was first said; c) the "crossroads mechanism", when the beginning of the joke is uninterpretable and the end of the joke allows it to be understood, although it can remain unclear.

18. Clark (1996) seems to be using an analysis of meaning (and irony?) in terms of layers; layers have the disavantage(s) of being both discrete and superimposed to each other. The discussion of whether there should be different levels of interpretation is of course central to all Gricean and post-Gricean pragmatics and these questions would need to be further developed. 
19. Other aspects of the theory can also be challenged: not everything that is incongruous is funny (manifestations of dementia can be incongruous, but they may not be funny), and not everything that is funny is incongruous (one-liners based on observational humour can, in fact, be tautological and be appreciated because they make the world more congruent rather than incongruous).

20. See Dynel (2010). One can distinguish default, used by Jaszczolt (2005), and preferred, used by Levinson (1983) in his discussion of conversation analysis. Only one aspect of the problem will be mentioned for the time being: the question of whether "default" or "preferred" readings have to be posited in one-liner analysis, and why.

21. Cultural references can have the same role, and the same effect, although they can also restrict the audience of a joke if too culture-specific.

22. The deviser and the hearer may need to be further differentiated (as opposed to Dynel 2010). Writing a one-liner is making a bet on what can be understood and trying to be funny. Part of this problem is mentioned in Section 3.

23. This may be reminiscent of Fauconnier's mental spaces (1984), but what we have in mind may not be self-contained "spaces" with one domain mapped onto another in a systematic way; partial colliding, or clashing, may be provoked, and connections of all forms may be present (some common to many, but individual differences have to be accommodated, too; see following paragraph and Section 3).

24. See Section 3.

25. Dynel mentions the fact that "the interpreter is aware of the humorous frame signalled by the speaker" (2012: 13).

\section{ABSTRACTS}

This paper examines one-liners from a linguistics point of view, using them to address the question of how meaning emerges in context. A typology of one-liners is first proposed, in which the devices that they rely on are first described and discussed. The paper then tackles the question of what they can illustrate of the contextual emergence of meaning, the emphasis being put on constructedness. The paper argues in favour of the presence of merged representations, as opposed to successive, discrete interpretations-one of which is cancelled in the course of "getting" the one-liner. Additional remarks are made on how interpretability and humour are not two aspects of one and the same question, and a short discussion is included of how the formal and the functional dimensions can interact.

Dans cet article, on envisage les one-liners (blagues courtes supposées constituer une seule réplique) à partir de problématiques linguistiques. Nous commençons par proposer une typologie dans laquelle les procédés principaux employés sont mis au jour, et les exemples sont décrits et commentés. La question de savoir ce que les one-liners peuvent dire de l'émergence contextuelle $\mathrm{du}$ sens est ensuite abordée en mettant l'accent sur la construction dynamique du sens. Nous montrons également l'importance de la présence d'interprétations fusionnées, que l'on peut opposer à des analyses supposant une succession entre une interprétation A et une autre interprétation B annulant l'interprétation A. Nous terminons en rappelant ou montrant que la dimension comique des one-liners n'est pas soluble dans les questions d'interprétabilité, et pour qu'un one-liner fonctionne, il faut certes, qu'il soit plutôt compréhensible, mais avant tout, qu'il 
soit drôle, ce qui conduit à une brève discussion des liens que la fonction humoristique des oneliners peut entretenir avec la question de leur interprétation.

\section{INDEX}

Keywords: one-liners, humour studies, semantics, pragmatics, contextual interpretation, interpretation, humour

Mots-clés: one-liners, études sur l'humour, sémantique, pragmatique, interprétation contextuelle, interprétation, humour

\section{AUTHOR}

\section{CATHERINE CHAUVIN}

Catherine Chauvin is a lecturer in English studies at Université de Lorraine (Nancy), where she teaches linguistics, grammar, phonetics and translation. She has written several papers on the expression of spatial relations (prepositions, particles, types of verbs, V-framed/ S-framed opposition), and has edited Sémantique des relations spatiales, Faits de Langues, Peter Lang (2013) on the topic. She has also written on coherence / cohesion, expressivity, degree marking, subjectless / verbless sentences, and reduplication; the studied language is English and/or English as contrasted to other languages. She is also interested in the non-linguistic representation of language problems, and has written one paper on the depiction of fictional dialects in literature; she has also recently given several papers on language and humour, focusing particularly on stand-up comedy. Contact: catherine.chauvin [at] univ-lorraine.fr 